\title{
PENDIMETHALIN APLICADO À CASCA DE ARROZ E SERRAGEM PARA O CONTROLE DE PLANTAS DANINHAS EM Ixora chinensis Lam.
}

\author{
Pendimethalin applied on rice husks and sawdust for weed control on Ixora chinensis Lam.
}

\author{
André Luis Seixas ${ }^{1}$, Pedro Luis da Costa Aguiar Alves², Leonardo Bianco de Carvalho ${ }^{3}$
}

\begin{abstract}
RESUMO
A aplicação de herbicidas residuais à coberturas mortas pode aumentar a eficiência desses materiais no manejo da comunidade infestante. Objetivou-se, com este trabalho, avaliar a possibilidade de aplicação do pendimethalin à casca de arroz e à serragem para o controle de plantas daninhas em Ixora chinensis. Dois experimentos foram conduzidos aplicando-se o pendimethalin às coberturas mortas através de embebição e pulverização do herbicida, variando-se também a quantidade de cobertura utilizada. As espécies de plantas daninhas que ocorreram com maior frequência foram Alternanthera tenella, Blainvillea rhomboidea, Cenchrus echinatus e Commelina benghalensis. Há possibilidade de aplicação do herbicida pendimethalin à palha de arroz ou à serragem para controle de plantas daninhas em I. chinensis, principalmente quando ocorrem chuvas regulares e bem distribuídas. Há evidências de que a embebição da cobertura morta no herbicida seja um pouco mais eficiente no controle das plantas daninhas que a sua pulverização sobre a cobertura. Possivelmente, a quantidade de cobertura morta utilizada influencia na eficiência de controle, apesar deste fato não ter ficado claro neste trabalho.
\end{abstract}

Termos para indexação: Coberturas mortas, herbicida, planta ornamental.

\begin{abstract}
Applying herbicides at mulches may increase the efficiency of these materials for weed management. The objective of this research was to evaluate the possibility of pendimethalin applied on rice husks and sawdust for weed control on Ixora chinensis. In two field trials, pendimethalin was applied to the mulches through imbibition and spraying herbicide, also varying the amount of mulches. Higher frequent weeds were Alternanthera tenella, Blainvillea rhomboidea, Cenchrus echinatus and Commelina benghalensis. There are possibility of pendimethalin application on rice husks or sawdust for controlling weeds in I. chinensis mainly when regular and well-distributed rainfalls occur. There are evidences that the imbibition of these mulches to the herbicide is a little more efficient for controlling weeds than the spraying herbicide on the mulches. Probably, the amount of mulches would influence in the control efficiency, although this fact had not been clear in this study.
\end{abstract}

Index terms: Mulches, herbicide, ornamental plant.

(Recebido em 14 de janeiro de 2009 e aprovado em 18 de novembro de 2010)

\section{INTRODUÇÃO}

A ixora (Ixora chinensis Lam.), uma das plantas ornamentais produzidas e comercializadas no Brasil, é muito utilizada em projetos paisagísticos devido ao porte arbustivo, ao florescimento constante e ao colorido de suas flores (LORENZI; SOUZA, 2001).

Nas áreas de paisagismo, assim como em culturas agrícolas, a presença de plantas daninhas pode causar transtornos e inconvenientes. Segundo Pitelli (1985), elas podem afetar o crescimento e o desenvolvimento das plantas com as quais convivem; competindo por água, luz e nutrientes; liberando aleloquímicos; hospedando pragas e doenças; interferindo na colheita e; consequentemente; reduzindo a produtividade da cultura de interesse econômico.
Nas áreas de paisagismo, a utilização de herbicidas é limitada, pois existem poucos produtos disponíveis no mercado. Assim, como alternativa para o controle de plantas daninhas, tem-se a aplicação de coberturas mortas sobre o solo (SEVERINO; CHRISTOFFOLETI, 2001), que é a prática frequentemente utilizada em áreas de paisagismo. Segundo Gassen e Gassen (1996), essa alternativa ainda protege o solo da radiação solar, dissipa a energia de impacto das gotas de chuva, reduz a evaporação de água e aumenta a eficiência da ciclagem dos nutrientes.

A aplicação de herbicidas residuais às coberturas mortas pode ser feita para aumentar a eficiência desses materiais no controle de plantas daninhas. Moreira et al. (1993), citados por Bezutte et al. (1995) constataram que a aplicação do oxyfluorfen à palha de arroz proporcionou

'Engenheiro Agrônomo - São José do Rio Preto, SP - seixasal@yahoo.com.br

2Universidade Estadual Paulista "Júlio de Mesquita Filho"/UNESP - Faculdade de Ciências Agrárias e Veterinárias/FCAV - Departamento de Biologia Aplicada à Agropecuária - Jaboticabal, SP

3Universidade Estadual Paulista "Júlio de Mesquita Filho"/UNESP - Faculdade de Ciências Agrárias e Veterinárias/FCAV - Jaboticabal, SP 
efetivo controle das plantas daninhas em hortaliças, não diferenciando da mesma dose sob pulverização. O pendimethalin veiculado à palha de arroz aumentou sua eficiência e o tempo de atividade em relação à mesma dose sob pulverização. Bezutte et al. (1995) verificaram que a aplicação de oxifluorfen (480 e $960 \mathrm{~g} \mathrm{ha}^{-1}$ ) em papel proporcionou excelente controle de Desmodium tortuosum (Sweet) DC., Eleusine indica (L.) Gaertn., Digitaria horizontalis Willd., Sida rhombifolia L. e Amaranthus retroflexus $\mathrm{L}$.

Por outro lado, apesar de ser alternativa interessante no manejo de plantas daninhas por proporcionar redução de custos, facilitar a aplicação, aumentar o tempo de atividade do produto, resultando em relação custo/beneficio rentável, e causar menores danos ao ambiente, pois o herbicida é depositado somente na área de interesse, eliminando a deriva (BEZUTTE et al., 1995); são poucos os trabalhos que exploram a aplicação de herbicidas residuais veiculados à coberturas mortas.

Objetivou-se, com este trabalho, avaliar a possibilidade de aplicação do herbicida pendimethalin, em diferentes coberturas mortas, para o controle de plantas daninhas em canteiros de I. chinensis.

\section{MATERIAL E MÉTODOS}

$\mathrm{Na}$ pesquisa, utilizaram-se dois experimentos instalados e conduzidos na Fazenda de Ensino, Pesquisa e Produção da FCAV/UNESP, localizada no município de Jaboticabal, São Paulo, Brasil, na latitude de $21^{\circ} 15^{\prime} 22^{\prime \prime S u l ~}$ e longitude de $48^{\circ} 18^{\prime} 58^{\prime \prime}$ Oeste. Segundo a classificação internacional de Koeppen, o clima da região é do tipo Cwa, em que, na época das águas, predominam as chuvas de verão, com inverno relativamente seco. A temperatura média do mês mais quente é superior a $22^{\circ} \mathrm{C}$ e a do mês mais frio, inferior a $18^{\circ} \mathrm{C}$, com precipitação média anual de $1.440 \mathrm{~mm}$. O solo (Latossolo Vermelho Escuro), de textura argilosa, apresentou $\mathrm{pH}\left(\mathrm{CaCl}_{2}\right)$ igual a 5,$1 ; 20,0 \mathrm{~g}$ $\mathrm{dm}^{-3}$ de M.O., 26,0 mg dm${ }^{-3}$ de P (resina); 1,9; 23,0; 14,0; 25,$0 ; 38,9 ; 63,9 ; 61,0 \mathrm{mmol}_{\mathrm{c}} \mathrm{dm}^{-3} \mathrm{de} \mathrm{K} ; \mathrm{Ca} ; \mathrm{Mg} ; \mathrm{H}+\mathrm{Al} ; \mathrm{SB}$; $\mathrm{T} ; \mathrm{V}$; respectivamente.

O preparo do solo foi semelhante nos dois ensaios, com duas gradagens, sendo uma pesada e outra leve, seguidas do levantamento dos canteiros com rotoencanteiradora. Em ambos os ensaios, utilizaram-se mudas comerciais de I. chinensis, formadas por estaquia, com quatro meses de idade e, aproximadamente, $30 \mathrm{~cm}$ de altura.

As parcelas experimentais apresentaram dimensões semelhantes nos dois ensaios. O espaçamento entre plantas foi $0,25 \times 0,25 \mathrm{~m}$. Cada parcela foi composta por doze plantas de I. chinensis (3x4). Nas avaliações da espécie ornamental, selecionaram-se apenas as duas plantas centrais como plantas úteis.

O primeiro ensaio foi instalado em delineamento de blocos casualizados com três repetições, constando de cinco tratamentos: aplicação de pendimethalin - Herbadox $500 \mathrm{CE}-(1,5 \mathrm{~kg}$ i.a. ha-1) veiculado a dois tipos de coberturas mortas - palha de arroz e serragem $\left(10 \mathrm{t} \mathrm{ha}^{-1}\right)$; dois tratamentos com as coberturas mortas sem herbicida e uma testemunha sem cobertura. Para quantificar a dose do herbicida veiculado às coberturas mortas, calculou-se, inicialmente, o poder de embebição da palha de arroz e da serragem, por meio da fórmula utilizada por Bezutte et al. (1995).

Foram efetuadas oito avaliações sobre a densidade de plantas daninhas, sendo as sete primeiras, semanalmente, a partir de 21 dias após a instalação do ensaio (DAI), e, a última, 87 DAI. Essas avaliações constaram de uma amostragem em $0,25 \mathrm{~m}^{2}$ na área útil das parcelas. Na última avaliação, as plantas úteis de I. chinensis e todas as plantas daninhas presentes na área amostrada foram coletadas para determinação da massa seca, após a secagem do material em estufa de circulação forçada de ar $\left(70^{\circ} \mathrm{C}\right)$ até peso constante.

O segundo ensaio foi instalado em delineamento de blocos casualizados com três repetições, constando de 15 tratamentos: aplicação do pendimethalin veiculado a 15 e $20 \mathrm{t} \mathrm{ha}^{-1}$ nos dois tipos de cobertura morta, seguindo procedimento de Bezutte et al. (1995), pulverizado sobre as coberturas ou diretamente sobre o solo nu. Consideraram-se testemunhas as parcelas com coberturas mortas sem aplicação de herbicida, as parcelas com capina e as parcelas sem capina das plantas daninhas.

A pulverização da calda herbicida foi feita com pulverizador costal de pressão $\left(\mathrm{CO}_{2}\right)$, à $40 \mathrm{lb} \mathrm{pol}^{-2}$, com duas pontas 110.02 e gasto de $200 \mathrm{~L} \mathrm{ha}^{-1}$ de calda, em condições de rajadas leves de vento, temperatura do ar $35^{\circ}$ $\mathrm{C}$ e do solo $38^{\circ} \mathrm{C}$ (a $5 \mathrm{~cm}$ ), nebulosidade de $20 \%$ e umidade relativa do ar de $40 \%$.

Foram efetuadas nove avaliações sobre a densidade de plantas daninhas, sendo as oito primeiras realizadas semanalmente, a partir de 14 DAI, e, a última, 107 DAI. A metodologia foi a mesma utilizada no primeiro experimento, salvo que a matéria seca das plantas de I. chinensis foi separada em folhas e caules.

Os dados de massa seca das plantas daninhas e da I. chinensis foram submetidos à análise de variância pelo teste F, sendo as médias comparadas pelo teste de Tukey a $5 \%$ de probabilidade. 


\section{RESULTADOS E DISCUSSÃO}

As espécies de plantas daninhas que ocorreram com maior frequência foram: Alternanthera tenella Colla (primeiro experimento), Blainvillea rhomboidea Cass. (segundo experimento), Cenchrus echinatus L. e Commelina benghalensis L. (primeiro e segundo experimentos).

No primeiro experimento, em que houve boa ocorrência e distribuição das chuvas (Figura 1A), os tratamentos com palha de arroz ou serragem embebidas em calda de pendimethalin proporcionaram redução substancial na densidade de plantas daninhas que conviviam com I. chinensis, em relação à testemunha sem controle (Figura 2). O tratamento com serragem sem embebição, por sua vez, proporcionou pequena redução na densidade de plantas daninhas. Porém, o tratamento com palha de arroz sem embebição permitiu o aumento na densidade de plantas daninhas, evidenciando não ter sido eficiente no controle das mesmas. Isso refletiu no acúmulo de massa seca das plantas daninhas, que foi semelhante entre a testemunha e o tratamento com palha de arroz sem herbicida, diferenciando-se dos demais (Figura 3A).

Contudo, todos os tratamentos porporcionaram crescimento semelhante das plantas de I. chinensis (Figura 3B). Porém, o tratamento com serragem embebida em calda de pendimethalin foi o único que diferiu da testemunha sem controle, evidenciando ser o melhor método de controle, dentre aqueles estudados.

No segundo experimento, em que houve menor ocorrência e pior distribuição das chuvas (Figura 1B), no geral, observou-se redução da densidade de plantas daninhas que conviviam com I. chinensis, em relação à testemunha sem controle (Figuras 4, 5 e 6), apesar da variabilidade dos resultados.

A aplicação direta do pendimethalin ao solo reduziu substancialmente a densidade de plantas daninhas em relação à testemunha sem controle (Figura 4). Dos tratamentos com palha de arroz, somente aquele em que a palha foi embebida no herbicida, apresentou redução substancial da densidade de plantas daninhas (Figura 5), assim como ocorreu com a serragem (Figura 6).

É importante destacar ainda que a aplicação de pendimethalin sobre o solo nu reduziu significativamente a densidade populacional de $C$. echinatus e das outras plantas daninhas durante todo o período de avaliação, enquanto as densidades populacionais de $B$. rhomboidea e $C$. benghalensis sofreram alterações infimas (Figuras 4A e 4B). Esse fato pode ser explicado pelo poder herbicida do pendimethalin sobre $C$. echinatus, e pelo fato de $B$. rhomboidea e $C$. benghalensis não estarem entre as principais espécies susceptíveis a esse herbicida (RODRIGUES; ALMEIDA, 2005).

A adição de cobertura morta sobre o solo contribuiu para aumento na germinação de todas as plantas daninhas avaliadas, à exceção de $C$. benghalensis (Figuras 5 e 6), em relação a testemunha no mato (Figura 4). Esse aumento deve-se, provavelmente, às alterações nas condições físicas do solo devido à adição da cobertura morta. A manutenção de restos vegetais na superfície do solo, além de proteger o solo da radiação solar, reduz a evaporação de água e a amplitude térmica e aumenta a eficiência da ciclagem dos nutrientes (GASSEN; GASSEN, 1996).
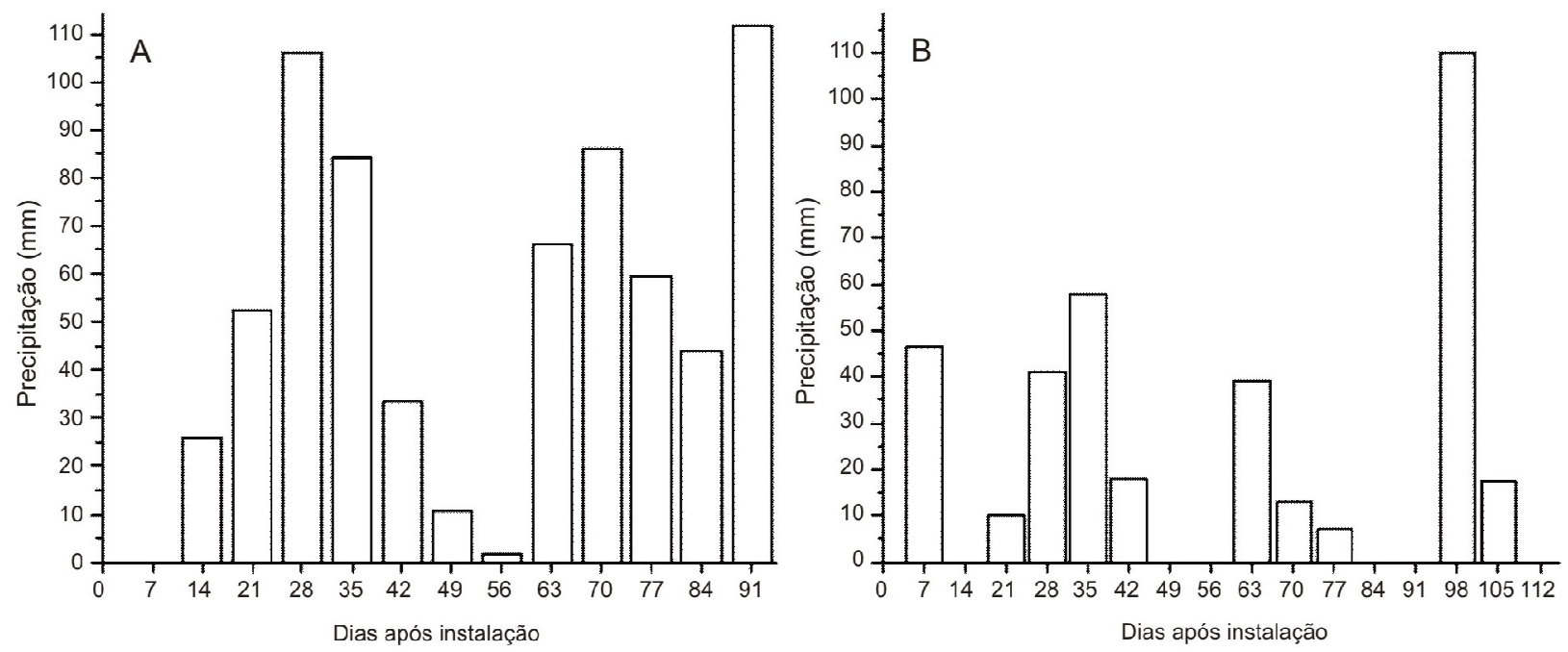

Figura 1 - Precipitação pluvial referente ao período de condução do primeiro (A) e do segundo (B) experimentos. 

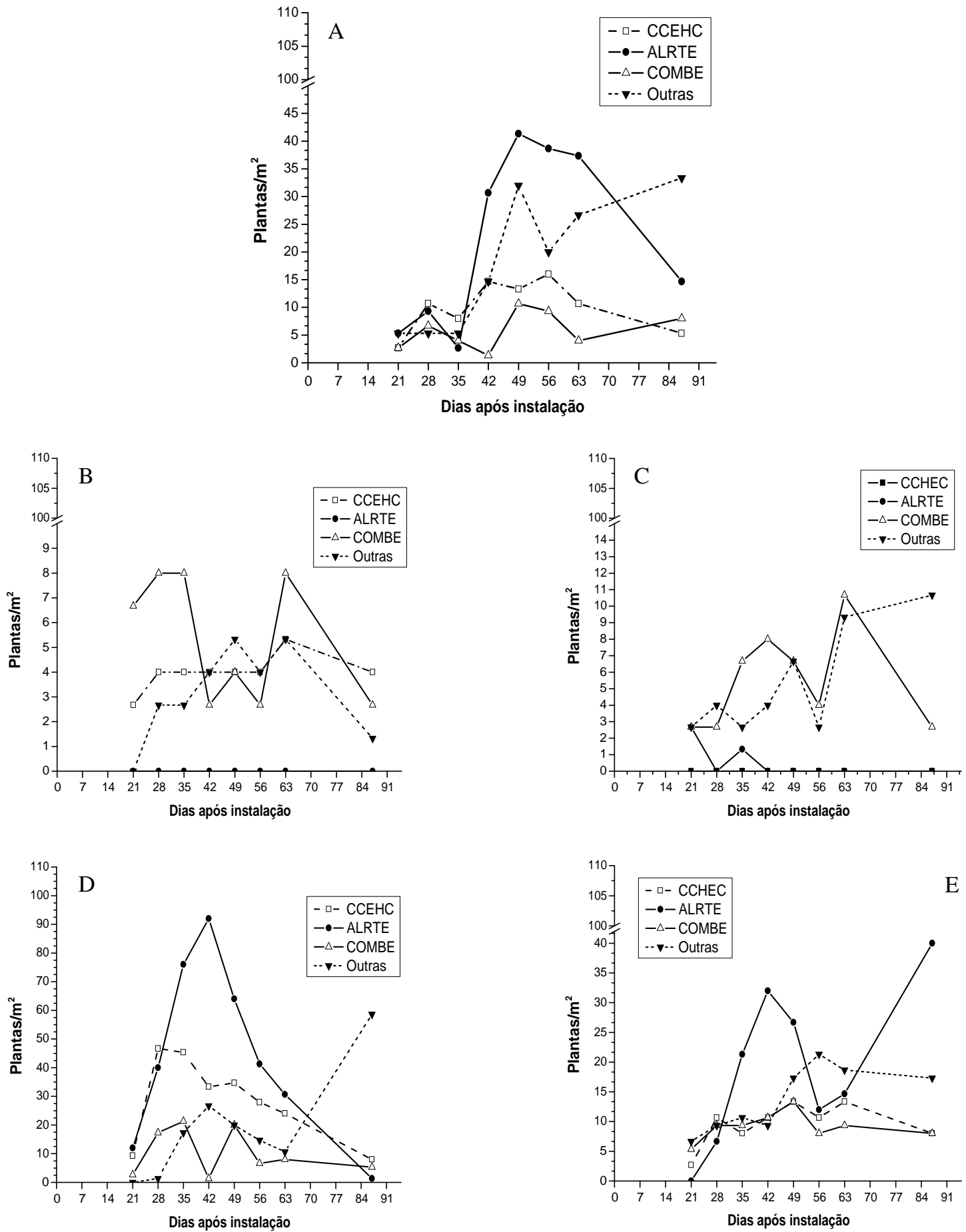

Figura 2 - Evolução da densidade populacional de plantas daninhas no primeiro experimento, nos tratamentos sem controle (A), com palha de arroz (B) ou serragem (C) embebida em calda de pendimethalin e palha de arroz (D) ou serragem (E) sem embebição. 

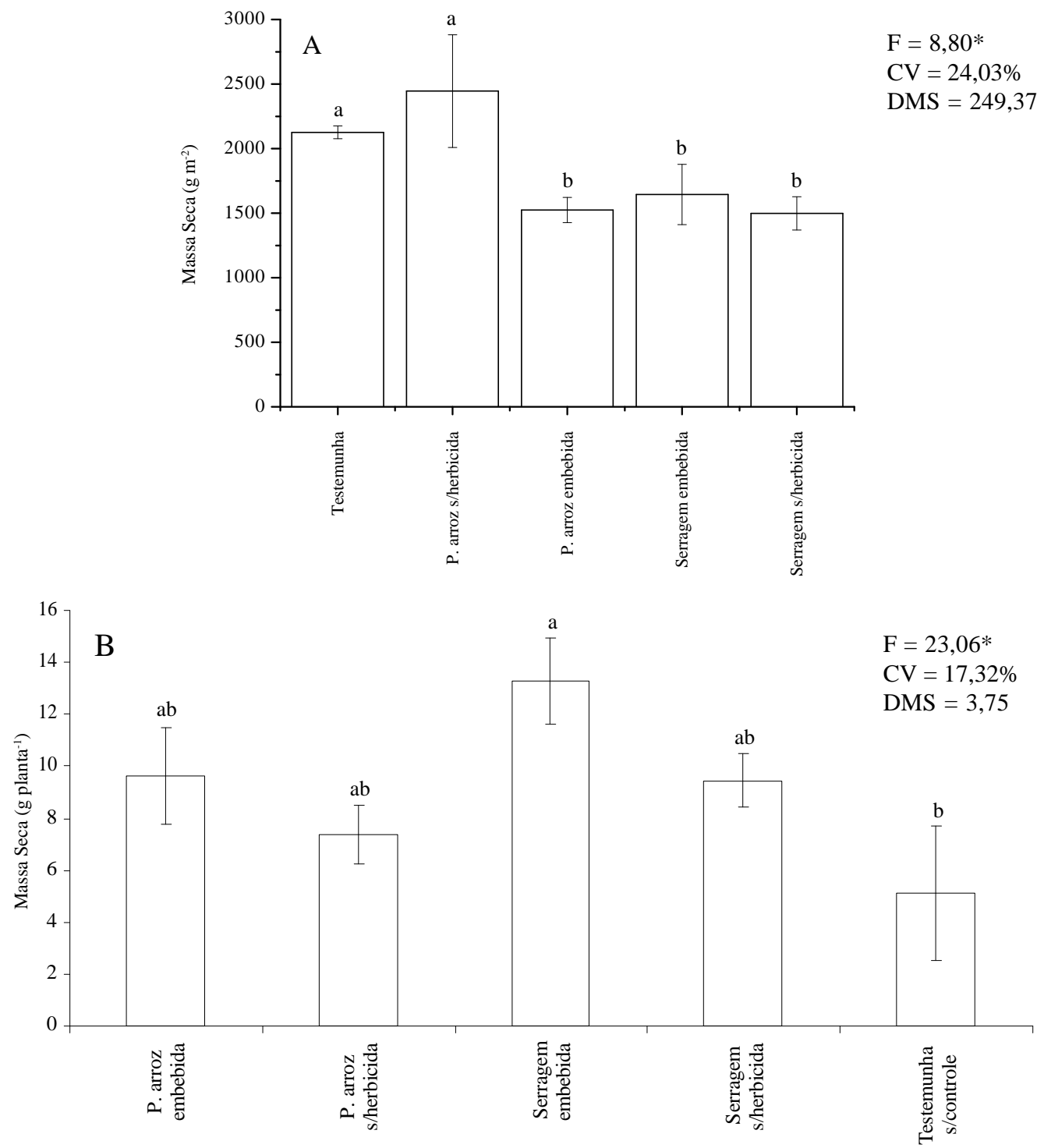

Figura 3 - Acúmulo de massa seca na parte aérea das plantas daninhas (A) e da Ixora chinensis (B) de acordo com o tratamento herbicida veiculado às coberturas mortas, aos 87 dias após a instalação do primeiro experimento. Barras verticais representam o erro padrão das médias. * indica significância a $5 \%$ pelo teste $\mathrm{F}$, sendo que CV indica o coeficiente de variação dos dados. Médias seguidas pela mesma letra não diferem entre si pelo teste de Tukey a 5\% de probabilidade, sendo que DMS indica a diferença mínima significativa entre as médias.

No geral, nos tratamentos em que se utilizaram $20 \mathrm{t}$ ha ${ }^{-1}$ de cobertura morta sem herbicida, a emergência das plantas daninhas foi menor em relação aos tratamentos com $15 \mathrm{t} \mathrm{ha}^{-1}$ (Figuras 5A-B e 6A-B). Isso se deve, provavelmente, aos efeitos físicos e químicos que a cobertura morta exerceu sobre a germinação das sementes das plantas daninhas. A cobertura do solo pode atuar como barreira física, impedindo a incidência de luz e a realização da fotossíntese por aqueles indivíduos que conseguiram emergir do solo, além de alterar a qualidade da luz incidente (FLECK; VIDAL, 1993; AZANIA et al., 2002).

Os tratamentos com $20 \mathrm{t}$ de serragem sem herbicida, $15 \mathrm{t}$ de palha de arroz ou serragem sem herbicida e $15 \mathrm{t}$ de palha de arroz pulverizada com pendimethalin permitiram que as plantas daninhas crescessem semelhantemente à testemunha sem controle (Figura 7A), 
evidenciando que estes não apresentaram bom controle das mesmas. Em contrapartida, os tratamentos com $20 \mathrm{t}$ de palha de arroz sem herbicida ou embebidas no herbicida, $20 \mathrm{t}$ de serragem embebidas ou pulverizadas com herbicida e $15 \mathrm{t}$ de palha de arroz embebidas no herbicida apresentaram controle semelhante ao tratamento com pulverização do pendimethalin diretamente ao solo, evidenciando que estes foram os melhores tratamentos em relação ao controle de plantas daninhas.

Todos os tratamentos proporcionaram crescimento das plantas de $I$. chinensis semelhante àquelas mantidas no limpo por meio de capina, a exceção de $20 \mathrm{t}$ de palha de arroz sem herbicida, $15 \mathrm{t}$ de serragem sem herbicida e serragem pulverizada com herbicida (Figura 7B).

Evidencia-se que a aplicação do pendimethalin às duas coberturas mortas, independentemente da quantidade, prolongou o efeito residual supressor do herbicida tanto no primeiro quanto no segundo experimento. Segundo Rodrigues e Almeida (2005), o efeito residual do pendimethalin no solo é de 60 dias, com meia vida chegando a 180 dias. Pivetta et al. (2008), com o intuíto de estudarem a possibilidade de veiculação do oxyfluorfen à palha de arroz e a sua seletividade à sálvia (Salvia splendens Sell. ex Roem. e Schult.), verificaram que o tratamento que proporcionou controle satisfatório de plantas daninhas sem causar danos às plantas de sálvia foi o que recebeu o herbicida na dose de $2 \mathrm{~L} \mathrm{ha}^{-1}$, veiculado a $4 \mathrm{t} \mathrm{ha}^{-1}$ de palha de arroz, enquanto a pulverização direta do herbicida sobre o solo e as plantas de sálvia não se mostrou viável.

Por outro lado, as coberturas do solo por si só, ou seja, sem tratamento com o herbicida, nem sempre foram eficientes no controle das plantas daninhas. Segundo Bezutte et al. (1995), o efeito supressor das coberturas mortas sobre a comunidade infestante é limitado. O período de decomposição da cobertura depende de vários fatores. A maioria dos fatores ambientais que afeta a decomposição de resíduos orgânicos está relacionada a sua ação sobre a atividade dos microrganismos decompositores, dentre eles, a temperatura e a umidade (QUEMADA, 2005), o teor de matéria orgânica do solo (GUPTA et al., 2004), a localização (COPPENS et al., 2007) e a quantidade de material adicionado (HADAS et al., 2004). Também exercem influência na decomposição as características químicas do resíduo vegetal, como a relação C/N (CERETTA et al., 2002), os teores de N, P, lignina e as relações C/P, lignina/ $\mathrm{P}$ e lignina/K do material (LUPWAYI et al., 2004), além do teor de polifenóis (PALM; SANCHEZ, 1991).

Ainda é importante evidenciar que, particularmente no segundo experimento, a má distribuição das chuvas pode ter contribuído para a variabilidade nos resultados, pois, embora sendo o pendimethalin um herbicida de baixa solubilidade e de pouca lixiviação (RODRIGUES; ALMEIDA, 2005), seu carácter lipofílico pode conferir-lhe comportamento diferenciado nas diferentes coberturas, em que ele ainda estaria sujeito a fotodegradação e volatilização (BEZUTTE et al., 1995).
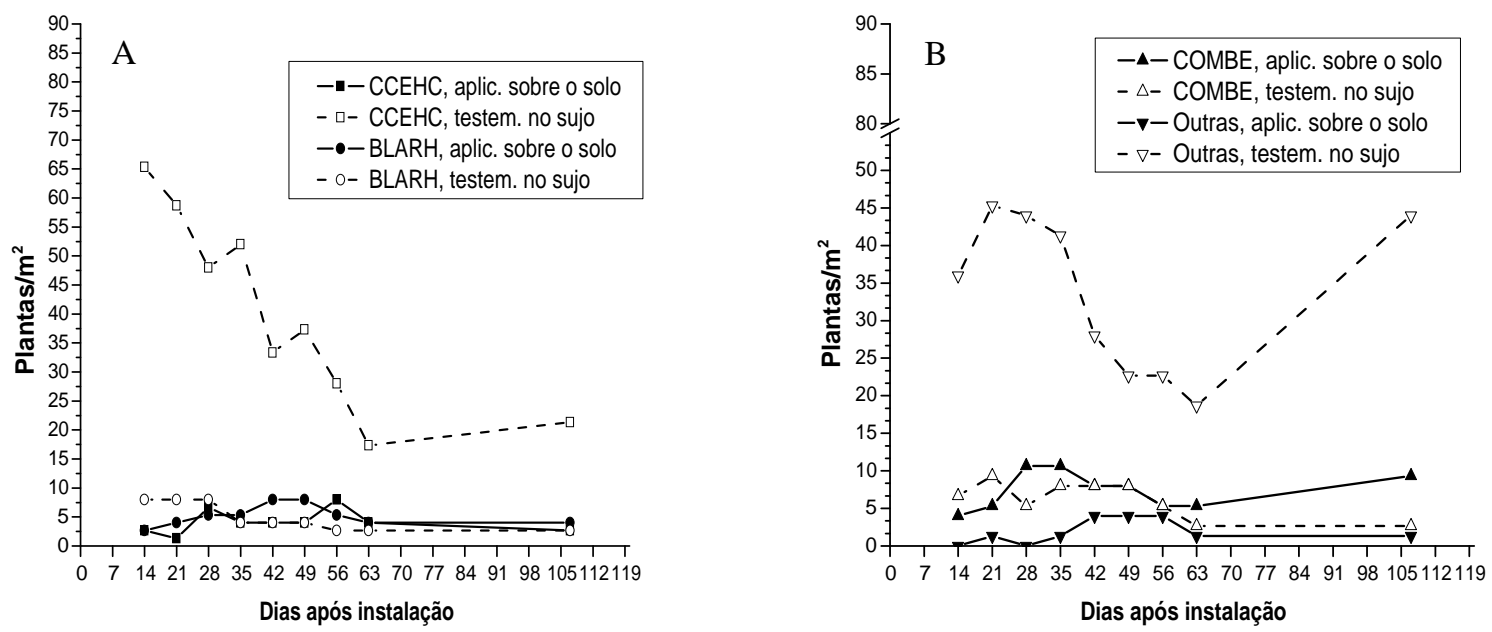

Figura 4 - Evolução da densidade populacional de plantas daninhas presentes no segundo experimento, nos tratamentos com pendimethalin aplicado sobre o solo e sem aplicação. 

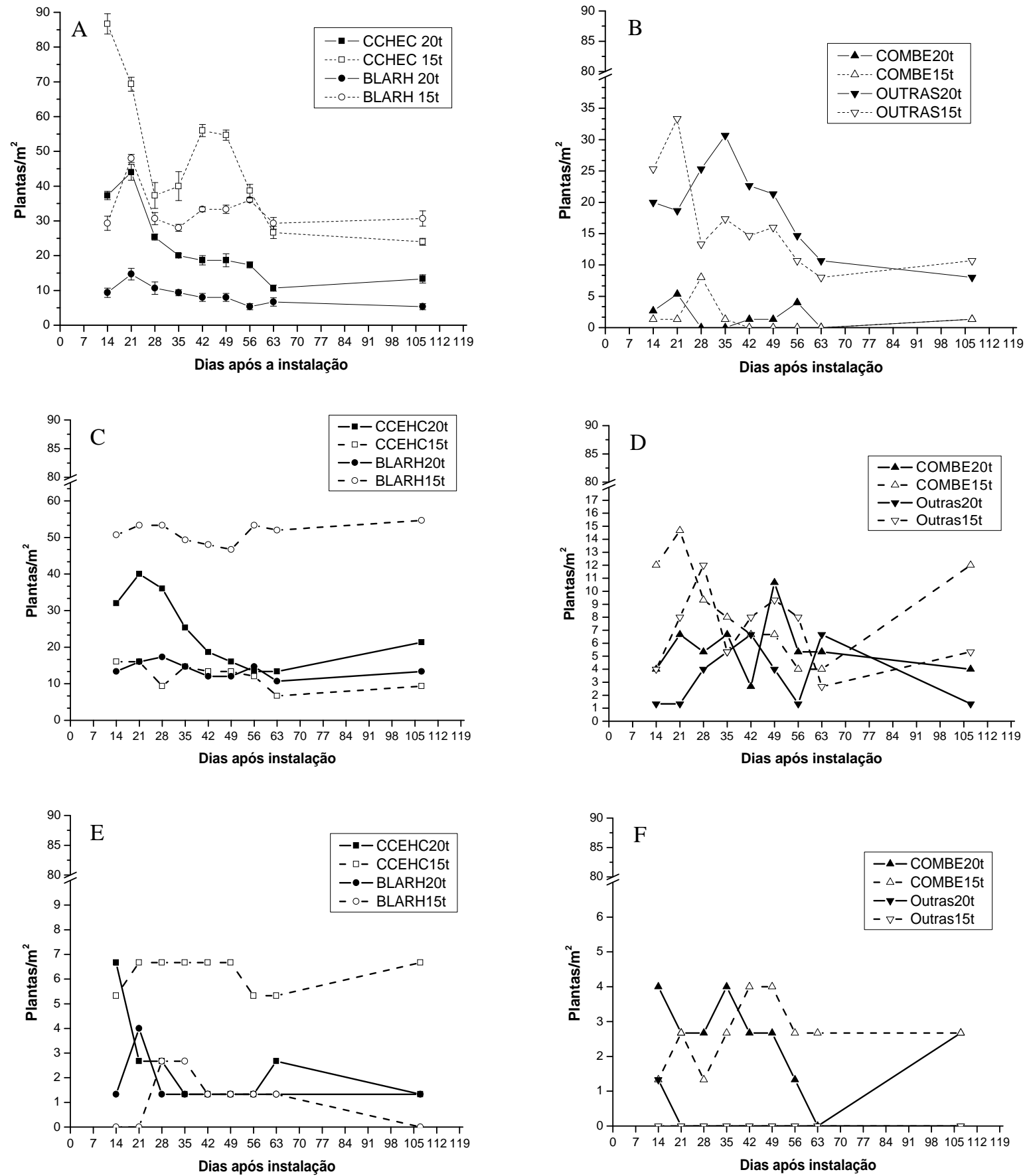

Figura 5 - Evolução da densidade populacional de plantas daninhas no segundo experimento, nos tratamentos com cobertura de palha de arroz sem aplicação de pendimethalin (A e B), com aplicação sobre a palha (C e D) e com a palha embebida em calda de pendimethalin (E e F). 

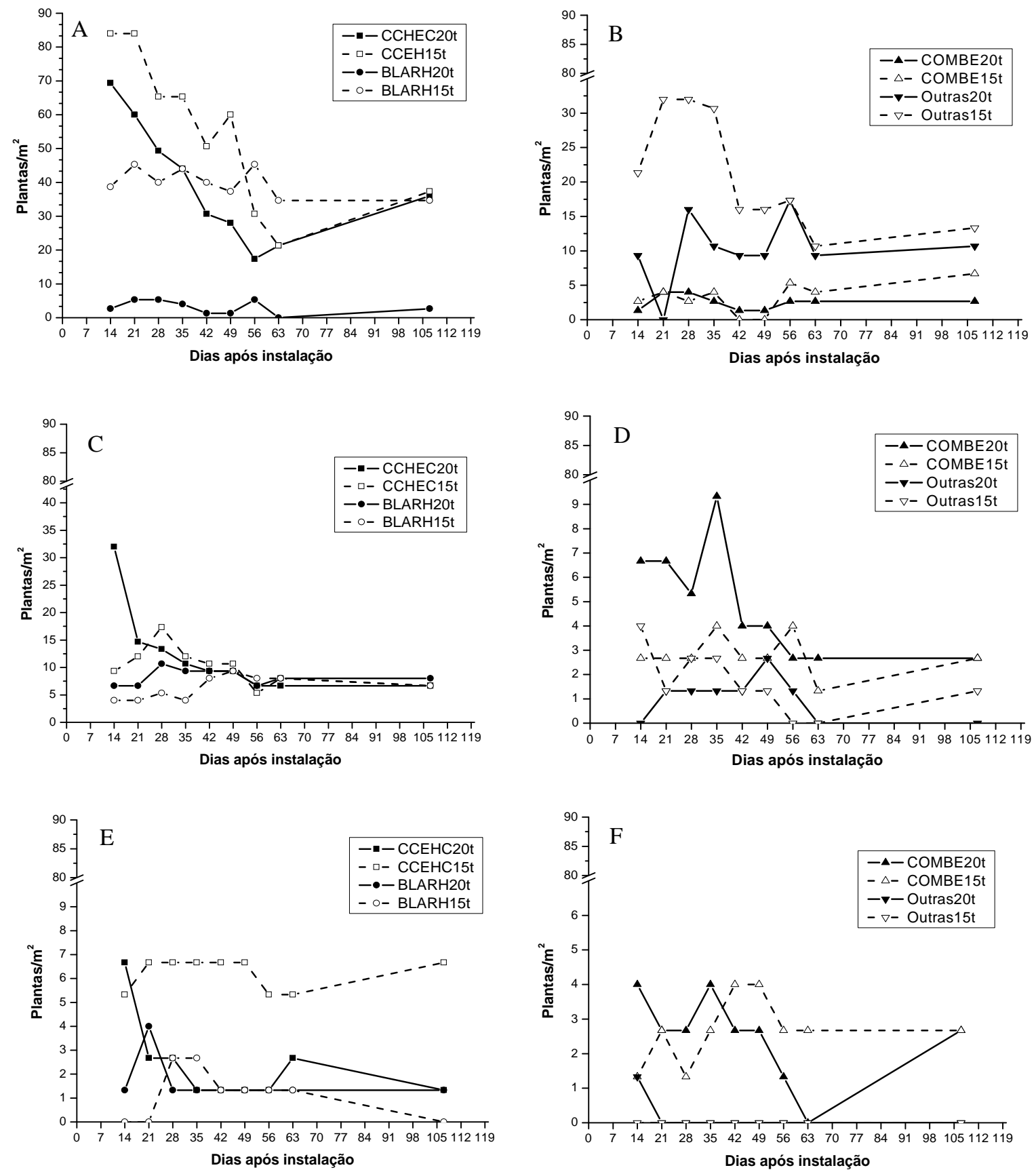

Figura 6 - Evolução da densidade populacional de plantas daninhas no segundo experimento, nos tratamentos com cobertura de serragem sem aplicação de pendimethalin (A e B), com aplicação sobre a serragem (C e D) e com a serragem embebida em calda de pendimethalin (E e F). 

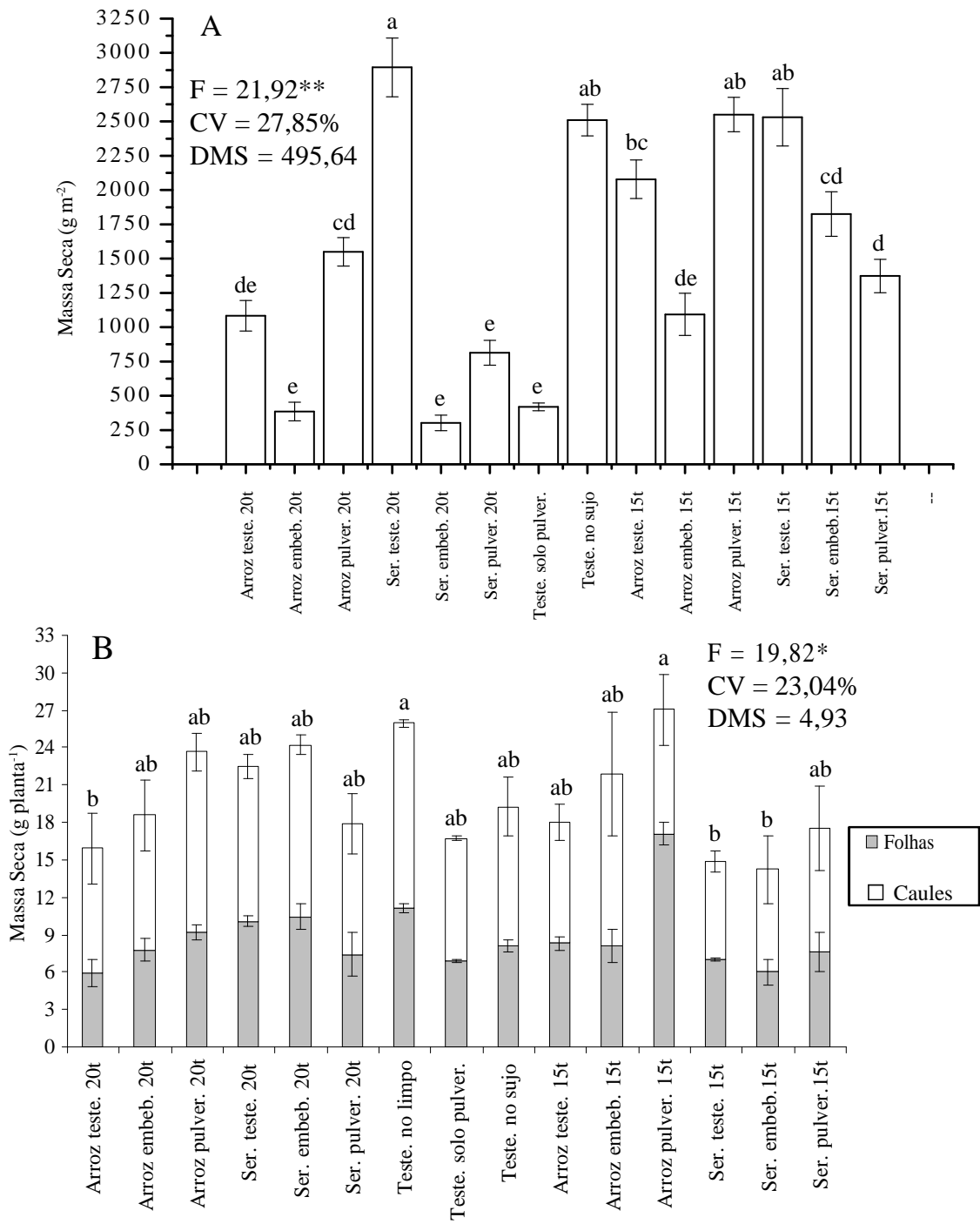

Figura 7 - Acúmulo de massa seca na parte aérea das plantas daninhas (A) e da Ixora chinensis (B) de acordo com o tratamento herbicida veiculado às coberturas mortas, aos 107 dias após a instalação do segundo experimento. Barras verticais representam o erro padrão das médias. *, ** indicam significância a 5\% e 1\% pelo teste $\mathrm{F}$, sendo que $\mathrm{CV}$ indica o coeficiente de variação dos dados. Médias seguidas pela mesma letra não diferem entre si pelo teste de Tukey a 5\% de probabilidade, sendo que DMS indica a diferença mínima significativa entre as médias.

\section{CONCLUSÕES}

Há possibilidade de aplicação do herbicida pendimethalin veiculado à palha de arroz ou à serragem para controle de plantas daninhas em I. chinensis, principalmente quando ocorrem chuvas regulares e bem distribuídas.

Há evidencias de que a embebição da cobertura morta no herbicida seja um pouco mais eficiente no controle das plantas daninhas que a sua pulverização sobre a cobertura.
Possivelmente, a quantidade de cobertura morta utilizada influencia na eficiência de controle, apesar desse fato não ter ficado claro neste trabalho.

\section{REFERÊNCIAS BIBLIOGRÁFICAS}

AZANIA, A.A.P.M. et al. Interferência da palha de canade-açúcar (Saccharum spp.) na emergência de espécies de plantas daninhas da família Convolvulaceae. Planta

Daninha, Viçosa, v.20, n.2, p.207-212, 2002. 
BEZUTTE, A.J. et al. Eficiência do herbicida oxyfluorfen veiculado ao papel no controle de algumas espécies de plantas daninhas. Planta Daninha, Viçosa, v.13, n.1, p.39-45, 1995.

CERETTA, C.A. et al. Produção e decomposição de fitomassa de plantas invernais de cobertura de solo e milho, sob diferentes manejos da adubação nitrogenada. Ciência Rural, v.32, n.1, p.49-54, 2002.

COPPENS, F. et al. Decomposition of mulched versus incorporated crop residues: Modelling with PASTIS clarifies interactions between residue quality and location. Soil Biology and Biochemistry, v.39, n.9, p.2339-2350, 2007.

FLECK, N.G.; VIDAL, R.A. Efeitos de métodos físicos de controle de plantas daninhas sobre características agronômicas do girassol. Pesquisa Agropecuária Brasileira, Brasília, v.28, n.11, p.1307-1318, nov. 1993.

GASSEN, D.N.; GASSEN, F.R. Plantio direto. Passo Fundo: Aldeia Sul, 1996. 207p.

GUPTA, S.B. et al. Effect of crop beneficial microbes on decomposition rate of different crop residues. Journal of Soils and Crops, v.14, n.1, p.1-4, 2004.

HADAS, A. et al. Rates of decomposition of plant residues and available nitrogen in soil, related to residue composition through simulation of carbon and nitrogen turnover. Soil Biology and Biochemistry, v.36, n.2, p.255-266, 2004.
LORENZI, H.; SOUZA, H.M. Plantas ornamentais no Brasil: arbustivas, herbáceas e trepadeiras. 3.ed. Nova Odessa: Instituto Plantarum, 2001. 1088p.

LUPWAYI, N.Z. et al. Decomposition of crop residues under conventional and zero tillage. Canadian Journal of Soil Science, v.84, n.4, p.403-410, 2004.

PALM, C.A.; SANCHEZ, P.A. Nitrogen release from the leaves of some tropical legumes as affected by their lignin and polyphenolic contents. Soil Biology and Biochemistry, Oxford, v.23, n.1, p.83-88, Jan. 1991.

PITELLI, R.A. Interferência das plantas daninhas nas culturas agrícolas. Informe Agropecuário, Belo Horizonte, v.11, n.129, p.16-27, 1985.

PIVETTA, K.F.L. et al. Seletividade de sálvia (Salvia splendens) ao herbicida oxyfluorfen veiculado à palha de arroz. Planta Daninha, Viçosa, v.26, n.3, p.645-655, 2008.

QUEMADA, M. Predicting crop residue decomposition using moisture adjusted time scales. Nutrient Cycling in Agroecosystems, v.70, n.3, p.283-291, 2005.

RODRIGUES, B.N.; ALMEIDA, F.S. Guia de herbicidas. 5.ed. Londrina: UEL, 2005. 591p.

SEVERINO, F.J.; CHRISTOFFOLETI, P.J. Efeitos de quantidades de fitomassa de adubos verdes na supressão de plantas daninhas. Planta Daninha, Viçosa, v.19, n.2, p.223-228, 2001. 